\title{
UMA ANÁLISE DO RTQ-R ENQUANTO FERRAMENTA DE AUXILIO AO PROJETO DE EDIFÍCIOS RESIDENCIAIS MAIS SUSTENTÁVEIS
}

\author{
Juliana Montenegro Matos (UFSC); Aldomar Pedrini (UFRN) \\ Orientador: Marcelo Bezerra de Melo Tinôco, Dr. (UFRN)
}

\section{INTRODUÇÃO}

Com o advento da energia elétrica e o desenvolvimento de novas tecnologias a partir do final do século XIX, a envoltória do edifício perdeu sua função de regulador térmico, passando-a aos sistemas artificiais de condicionamento térmico e iluminação. Assim, o arquiteto deixou de utilizar o clima local a seu favor, o que resultou em enormes prejuízos econômicos e ambientais. A produção de energia necessária para suprir as novas demandas passou a ser a causa de grande parte dos problemas ecológicos e econômicos atuais. A eficiência energética é, portanto, um dos principais fatores para o incremento da sustentabilidade nas edificações.

Hoje, a busca pelo conforto ambiental associado à necessidade de economizar energia, impõe a adoção de estratégias projetuais eficientes. Estas estratégias devem possuir estreita relação com o clima local e ser definidas na fase do projeto, pois é nesta etapa que as soluções são adotadas e os materiais e técnicas especificados (CARVALHO \& SPOSTO, 2014).

Os instrumentos legais votados para a avaliação do desempenho energético nas edificações são essenciais para a consolidação destas estratégias. Eles podem existir na forma de códigos, tais como guias, normas, leis, pro- tocolos, recomendações e regulamentos ou na forma de certificações ou sistemas de etiquetagem (SANTOS \& SOUZA, 2008).

No Brasil, o desenvolvimento destes instrumentos foi impulsionado pela crise energética de 2001, que levou à promulgação da Lei no 10.295 de 2001, que dispõe sobre a Política Nacional de Conservação e Uso Racional de Energia e do Decreto 4.059 de 2001 que a regulamenta. Esta legislação alavancou uma série de iniciativas, entre elas, o lançamento do Regulamento Técnico da Qualidade do Nível de Eficiência Energética de Edifícios Comerciais, de Serviços e Públicos (RTQ-C) e do Regulamento Técnico da Qualidade do Nível de Eficiência Energética de Edifícios Residenciais (BRASIL, 2010) através do Programa Nacional de Eficiência Energética em Edificações (Procel-Edifica), lançado pela Eletrobrás/Procel.

Este resumo expandido apresenta os resultados da pesquisa realizada com o objetivo de analisar a tendência de desempenho de características tipológicas na classificação do nível de eficiência energética da envoltória de edifícios residenciais verticais localizados em Natal/RN, segundo o método prescritivo do Regulamento Técnico da Qualidade do Nível de Eficiência Energética de Edifícios Residenciais (RTQ-R). 


\section{PROCEDIMENTOS METODOLÓGICOS}

O método utilizado se divide em quatro etapas principais: a) seleção de edifícios; b) levantamento de características primárias e secundárias; c) formulação de modelos de análise; e d) diagnóstico e análise qualitativa.

Foram estudados 22 edifícios residenciais construídos entre 2005 e 2010, selecionados com base na representatividade da empresa construtora no mercado local (medida em metros quadrados construídos).

A partir dos projetos arquitetônicos e memoriais descritivos fornecidos pelas mesmas, foram levantadas características primárias (referentes à forma, às dimensões, ao tipo de condicionamento de ar, às cargas internas e ao padrão de uso) e características secundárias (relacionadas a aspectos construtivos como a absortância solar, a transmitância e a capacidade térmica das superfícies, o coeficiente de sombreamento e o fator solar dos elementos translúcidos) (CARLO, 2008).

Os modelos de análise formulados consistem em protótipos virtuais elaborados com base nas tipologias formais e características construtivas predominantemente identificadas.

Estes modelos foram submetidos ao método prescritivo do RTQ-R para análise da envoltória, que utiliza basicamente uma equação matemática elaborada para cada zona bioclimática brasileira para classificação da envoltória de cada ambiente de permanência prolongada em uma escala de 1 a 5 (do menos eficiente para o mais eficiente). Em seguida os valores são ponderados pelas áreas dos ambientes para calcular o nível de eficiência da envoltória da unidade habitacional, além de considerar, ainda, o atendimento a itens obrigatórios e bonificações.
Desta forma, foram identificadas quais tipologias apresentavam melhor desempenho segundo esta metodologia. Posteriormente, foram propostas algumas modificações nos modelos de forma a identificar formas de se obter resultados mais favoráveis. É importante ressaltar que nem sempre essas modificações se alinharam aos aportes teóricos do conforto ambiental.

\section{RESULTADOS}

Foram elaborados seis modelos de análise variando o número de ambientes e a forma, indo da mais alongada para a mais compacta. As figuras 1 e 2 apresentam os modelos 5 e 6 . Percebeu-se que os edifícios residenciais verticais em Natal, representados pelos modelos formulados, apresentam características de projeto semelhante àquelas comumente utilizadas nas regiões Sul e Sudeste, apesar da disparidade climática. Assim, predominam tipologias formais compactas e orientadas para o Leste-Oeste, além da utilização de grandes janelas envidraçadas sem proteção solar.

Os modelos com forma retangular alongada permitem a orientação favorável de todas as unidades habitacionais em relação à insolação e à ventilação natural. Por outro lado, possuem alto percentual de área de parede externa. Os modelos mais compactos, por sua vez, possuem menos área de parede externa, mas implica em unidades habitacionais voltadas para direções opostas, impedindo que todas sejam orientadas da forma mais favorável.

Figura 1: Modelo de análise 5

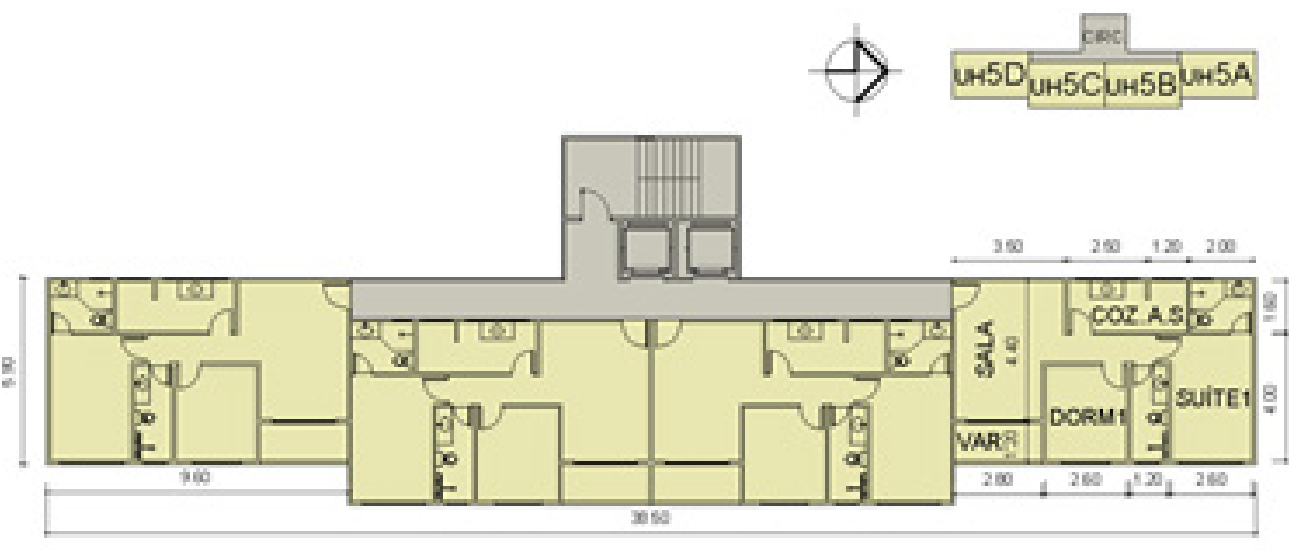

Fonte:Matos (2012) 
Figuras 2 - Modelo de análise 6
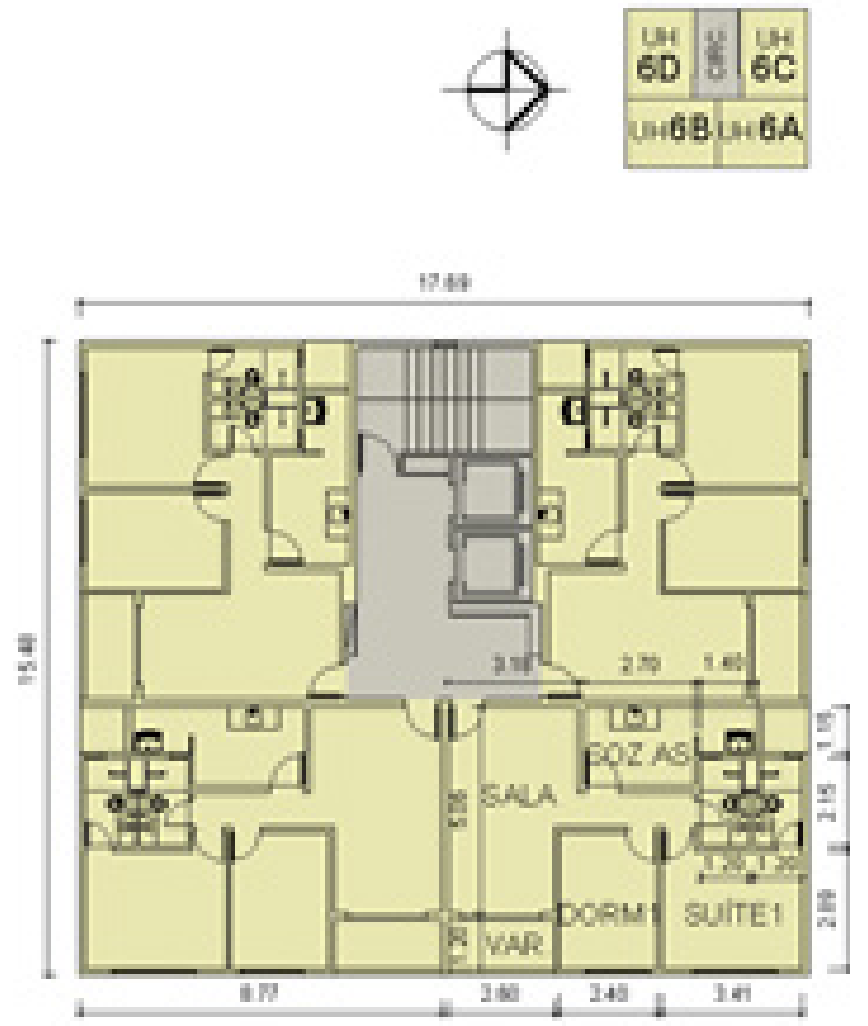

Fonte: Matos (2012).

Com base nos resultados obtidos, observou-se que a forma e a orientação do pavimento, o número e a orientação das paredes externas e aberturas, bem como o sombreamento destas e a distribuição espacial dos ambientes na planta do apartamento são características com grande influência sobre o desempenho da envoltória das unidades habitacionais e também com considerável potencial de melhoramento. Percebeu-se, também, que o número de paredes externas mesmo que com área mínima compromete a classificação do ambiente.

\section{CONSIDERAÇÕES FINAIS}

Como o número de paredes externas teve grande influência nestes resultados, e está diretamente relacionado à compacidade do pavimento (como pode ser observado no quadro 1), conclui-se que, do ponto de vista do método utilizado, os modelos mais compactos são mais passíveis de obtenção de classificações mais altas do que os modelos mais alongados, em de

Quadro 1 - Comparação entre os desempenhos dos modelos de análise.

\begin{tabular}{|c|c|c|c|}
\hline MODELO & CLASSIFICAÇÃO & MODELO & CLASSIFICAÇÃO \\
\hline 1 & 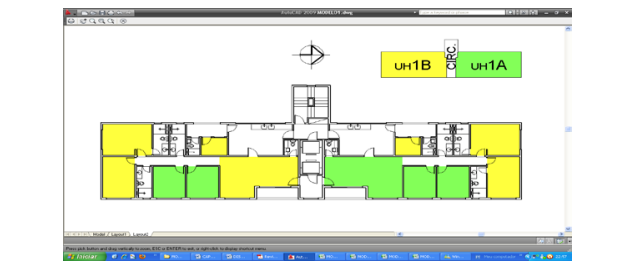 & 2 & 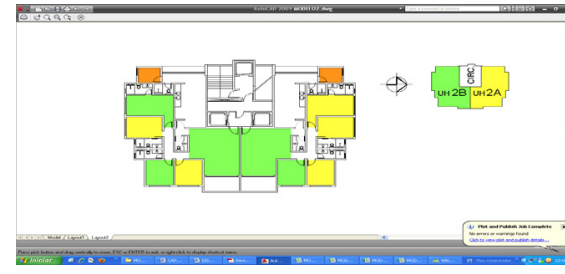 \\
\hline 3 & 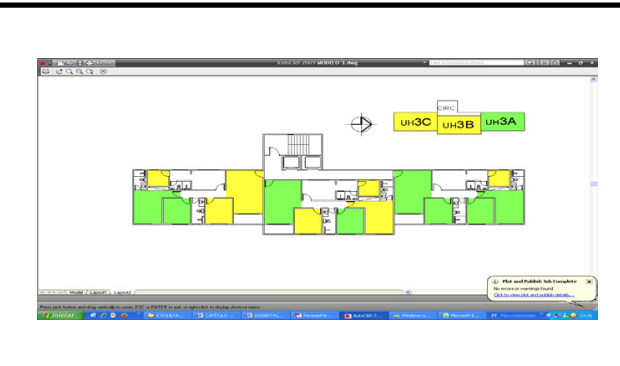 & 4 & 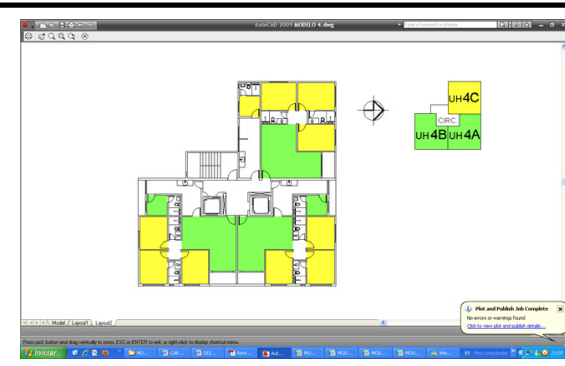 \\
\hline 5 & 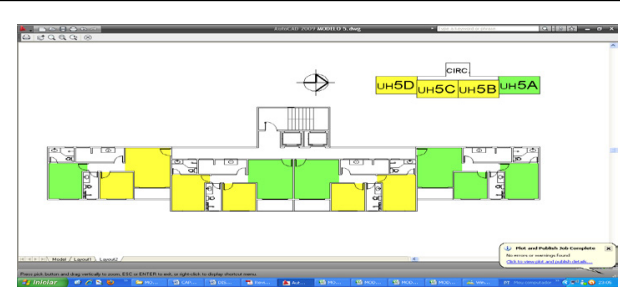 & 6 & 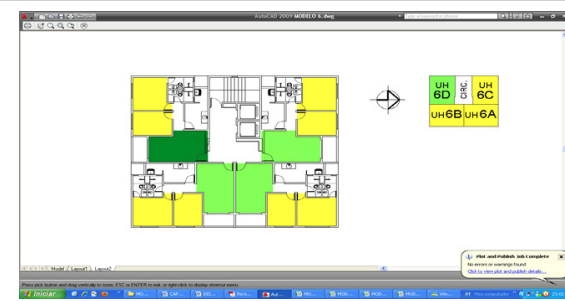 \\
\hline
\end{tabular}

Fonte: Matos (2012). 
trimento das principais recomendações para o clima quente e úmido de acordo com diversos autores estudados, como Pedrini e Lamberts (2003).

\section{REFERÊNCIAS}

BRASIL. INMETRO - Instituto Nacional de Metrologia. Regulamento Técnico da Qualidade para o nível de eficiência energética de Edificações Residenciais - RTQ-R. Rio de Janeiro, 2012.

CARLO, J. C. Desenvolvimento de Metodologia de Avaliação da Eficiência Energética do Envoltório de Edificações Não- Residenciais. Tese (Doutorado em Engenharia Civil) - Programa de Pós-Graduação em Engenharia Civil, Universidade Federal de Santa Catarina, UFSC, 2008.

CARVALHO, M. T. M.; SPOSTO, R. M.. Metodologia para avaliação da sustentabilidade de habitações de interesse social com foco no projeto. gulamentações em eficiência energética: uma atualização das últimas décadas. Revista Forum Patrimônio. UFMG. 2008. Disponível em: http:// www.forumpatrimonio.com.br/view_abstract. php?articlelD $=109 \&$ modo $=1$. Acesso em agosto 04 mar. 2014.

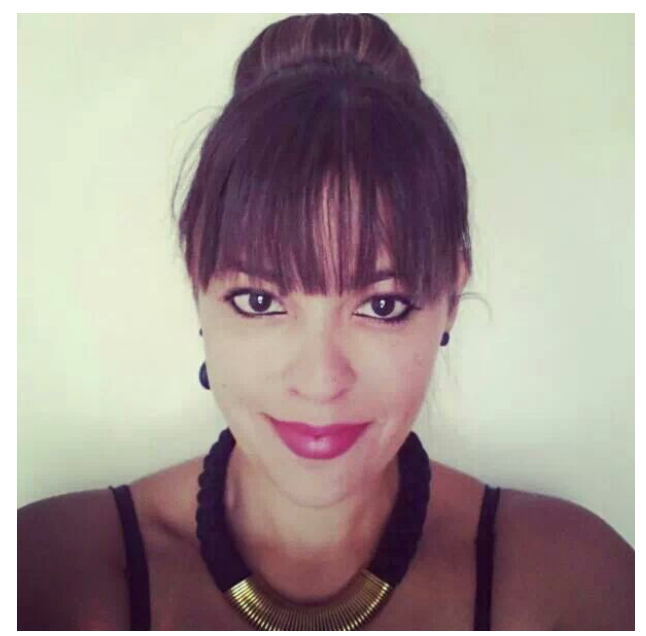
12, n. 1, p. 207-225, jan./mar. 2012. Disponível em: http://www.scielo.br/pdf/ac/v12n1/v12n1a14. pdf. Acesso em 09 mar. 2014.

MATOS, J. M.; Análise da Envoltória à Luz do Regulamento Técnico da Qualidade para o Nível de Eficiência Energética de Edificações Residenciais (RTQ-R) em Tipologias Verticais no Município de Natal/RN. Dissertação (Mestrado em Arquitetura e Urbanismo) - Programa de Pós-Graduação em Arquitetura e Urbanismo, Universidade Federal do Rio Grande do Norte, 2012.

PEDRINI, A.; LAMBERTS, R. Influência do tamanho e forma sobre o consumo de energia de edificações de escritório em clima quente. In: VII Encontro Nacional sobre Conforto no Ambiente Construído. Anais... Curitiba: ANTAC, 2003. pp. 209-216

SANTOS, I. G.; SOUZA, R. V. G. Revisão de re- 